\title{
Neutralization of MERS coronavirus through a scalable
} nanoparticle vaccine

Mona O. Mohsen ${ }^{1,2,3 凶}$, Dominik Rothen ${ }^{1,2}$, Ina Balke iD ${ }^{4}$, Byron Martina ${ }^{5,6}$, Vilija Zeltina ${ }^{4}$, Varghese Inchakalody ${ }^{3}, Z^{2}$ ahra Gharailoo ${ }^{1,2}$, Gheyath Nasrallah (D), Said Dermime (D) $^{3}$, Kaspars Tars ${ }^{4}$, Monique Vogel ${ }^{1,2}$, Andris Zeltins ${ }^{4}$ and Martin F. Bachmann (iD ${ }^{1,2,8,9}$

MERS-CoV continues to cause human outbreaks, so far in 27 countries worldwide following the first registered epidemic in Saudi Arabia in 2012. In this study, we produced a nanovaccine based on virus-like particles (VLPs). VLPs are safe vaccine platforms as they lack any replication-competent genetic material, and are used since many years against hepatitis B virus (HBV), hepatitis E virus (HEV) and human papilloma virus (HPV). In order to produce a vaccine that is readily scalable, we genetically fused the receptorbinding motif (RBM) of MERS-CoV spike protein into the surface of cucumber-mosaic virus VLPs. The employed CuMV ${ }_{\Pi T}$ VLPS represent a new immunologically optimized vaccine platform incorporating a universal $\mathrm{T}$ cell epitope derived from tetanus toxin (TT). The resultant vaccine candidate $\left(\mathrm{mCuMV}_{\Pi \mathrm{T}}-\mathrm{MERS}\right)$ is a mosaic particle and consists of unmodified wild type monomers and genetically modified monomers displaying RBM, co-assembling within $E$. coli upon expression. $\mathrm{mCuMV}_{\pi}-\mathrm{MERS}$ vaccine is selfadjuvanted with ssRNA, a TLR7/8 ligand which is spontaneously packaged during the bacterial expression process. The developed vaccine candidate induced high anti-RBD and anti-spike antibodies in a murine model, showing high binding avidity and an ability to completely neutralize MERS-CoV/EMC/2012 isolate, demonstrating the protective potential of the vaccine candidate for dromedaries and humans.

npj Vaccines (2021)6:107; https://doi.org/10.1038/s41541-021-00365-w

\section{INTRODUCTION}

Over the past two decades, different highly pathogenic coronaviruses caused several major outbreaks as seen with severe acute respiratory syndrome (SARS) in 2002 in China, Middle East Respiratory Syndrome (MERS) in 2012 in Saudi Arabia ${ }^{1}$ and most recently with the severe outbreak of SARS-CoV-2 that started in Wuhan city of China in $2019^{2}$. Following the first registered MERS epidemic in 2012 in Saudi Arabia, MERS-CoV continues to cause outbreaks in animals and humans in $>27$ countries worldwide including Saudi Arabia, Qatar, Oman, United Arab Emirates, Bahrain, Egypt, Jordan, USA, UK as well as China.

The WHO MERS report, published on January 2020 has recorded a total number of 2519 confirmed cases including 866 associated deaths (case-fatality rate of $34.3 \%$ ) worldwide. The majority of the cases were reported in Saudi Arabia. Death occurred in patients between 45-85 years with comorbidities and no changes in the demographic and epidemiological characteristics have been reported when compared to the periods in 2014-2020 ${ }^{3}$. Interestingly, a recent case series study has reported that $12 \%$ of the total numbers of MERS-infected cases admitted to the intensive care unit (ICU) (from March 14, 2020 to October 19, 2020) showed coinfection with SARS-CoV- $2^{4}$. This study raises new concerns of the possibility of interaction between both coronaviruses.

Similar to other coronaviruses, MERS-CoV is a zoonotic virus originating from bats, which probably serve as natural reservoirs (Lu et al., 2015), while dromedary camels most likely are intermediate hosts where the virus, however, remains endemic and causes mild symptoms similar to seasonal CoVs in humans (Abdulaziz N. Alagaili et al., 2015). Transmission of MERS-CoV among humans is considered rare but yet very possible. Due to the high mortality rate of MERS virus ( 25-35\%), the WHO declared the need for effective countermeasures such as vaccines for dromedaries as well as for humans. Indeed, this human to human transmissible disease represents a major threat and should gain political and public health attention before a next major outbreak.

Coronaviruses infect host cells via their spike glycoprotein which consists of S1 and S2 subunits. The S1 of MERS-CoV is encoded by amino acids (a.a.) 376-606 and contains the receptorbinding domain (RBD) that is composed of a core subdomain and a receptor-binding motif (RBM; a.a. 484-567). The RBM is the main domain that interacts with the DPP4 receptor and facilitates viral entry into target cells $s^{5,6}$. After attaching to the cell surface, peptidases from the host cleave the $S$ proteins, exposing the fusion peptide located in the S2 subunit. Such process leads to fusion of the viral and host cell membranes which enables the viral genome to enter the host cell. As for many other viruses, fusion mostly occurs in endosomes causing the release of the viral genome into the host cytosol. Finally, the viral RNA becomes available for translation and replication, resulting in assembly and packaging of new viral particles which are released from the cell?. Accordingly, the RBD and in particular the RBM domain may be considered the principal target against MERS-CoV for vaccine development.

Previous approaches for developing MERS-CoV vaccines included DNA vaccines, viral vectors, protein-based platforms or inactivated viruses ${ }^{8}$. The delivery of MERS-CoV $S$ antigen by means of DNA vaccination ${ }^{9}$, viral vectors (modified vaccinia Ankara MVA

\footnotetext{
${ }^{1}$ Department of BioMedical Research, University of Bern, Bern, Switzerland. ${ }^{2}$ Department of Immunology RIA, University Hospital Bern, Bern, Switzerland. ${ }^{3}$ Translational Cancer Research Facility and Clinical Trials Unit, Interim Translational Research Institute, Hamad Medical Corporation, Doha, Qatar. ${ }^{4}$ Latvian Biomedical Research \& Study Centre, Ratsupites iela1, Riga, LV, Latvia. ${ }^{5}$ Erasmus Medical Center, department of Viroscience, Rotterdam, The Netherlands. ${ }^{6}$ Artemis Bio-Support, Delft, The Netherlands. ${ }^{7}$ Research Complex, Qatar University, Doha, Qatar. ${ }^{8}$ Jenner Institute, Nuffield Department of Medicine, University of Oxford, Oxford, UK. ${ }^{9}$ International Immunology Centrer, Anhui Agricultural University, Hefei, China. ${ }^{凶}$ email: mona.mohsen@dbmr.unibe.ch
} 
or adenovirus) ${ }^{10,11}$, nanoparticles ${ }^{12}$ or RBD-based subunit vaccines $^{13}$ have proved efficacy in preclinical models against MERS$\mathrm{CoV}$. Several vaccines are currently in phase I clinical trials. Despite the promising results and active research on this area, neither antiviral drugs nor vaccines have been approved for veterinary or medical use against MERS ${ }^{14}$.

Virus-like particles (VLPs) are nanoscale multiprotein particles that mimic real viruses. In comparison to inactivated or liveattenuated vaccine platforms, VLP-based vaccines are capable of inducing a robust humoral immune response without the risk of reversion to virulence ${ }^{15}$ and do not require BSL-3 facility. Due to their nano-size dimensions, they readily reach draining lymph nodes where they induce a strong immune response ${ }^{16,17}$. Such rapid draining kinetics improves the exposure of $B$ cells to native VLPs and reduces potentially systemic inflammatory responses ${ }^{18}$. The traditional VLP platform has been used in several marketed vaccines against Hepatitis B Virus (HBV), Hepatitis E Virus (HEV), Human Papilloma Virus (HPV) as well as malaria ${ }^{19}$.

Cucumber mosaic virus-like particles (CUMV-VLPs) are derived from a plant virus. We have recently developed an immunologically optimized platform based on CUMV-VLPs, by incorporating a universal tetanus toxin (TT), a $T$ helper $\left(T_{H}\right)$ cell epitope into the particle $\left(\mathrm{CuMV}_{\Pi}-\mathrm{VLPs}\right)^{20}$. This results in enhanced $\mathrm{B}$ cell / $\mathrm{T}_{\mathrm{H}}$ cell interactions, especially important for elderly people and individuals with weak immune responses. This platform has reached several proofs of concepts in various animal species (reviewed $\mathrm{in}^{20,21}$ ). Furthermore, our newly developed vaccine platform is selfadjuvanted with prokaryotic ssRNA which is packaged within VLPs during the expression and assembly process in $E$. coli. The selfpackaged adjuvant serves as TLR7/8 ligand and promotes the activation of antigen-presenting cells (APCs) and B cells ${ }^{22-25}$.

Several methods can be used to display antigen epitopes on the surface of VLPs; these methods include chemical coupling and genetic fusion techniques. In our previous studies we used chemical coupling strategies such as SMPH or Cu-free click chemistry cross-linkers ${ }^{26-28}$. In this study, we have chosen to genetically insert the viral antigen into the VLP protein, enabling future GMP-compatible production at very large scale at low cost. The size of the engineered $\mathrm{mCuMV}_{\Pi \Pi}$-MERS particles are in the nanoscale of $\sim 40-50 \mathrm{~nm}$ and densitometric analysis suggests an approximate $40 \%$ incorporation of RBM. On the surface of the VLPs, RBM exhibits the right conformation as demonstrated by binding of the viral receptor DPP4. Here we show that our new vaccine is immunogenic in murine models and induces high RBD and spike specific -antibody titers which are capable of blocking the replication of MERS-CoV/EMC/2012 isolate in vitro.

\section{RESULTS}

\section{Efficient incorporation of MERS receptor-binding motif (RBM)} into mosaic CuMV $_{T T}$ nanoparticles

We have used our immunologically optimized plant-derived cucumber-mosaic VLPs $\left(\mathrm{CuMV}_{T_{T}}\right.$-VLPs) to develop a $\mathrm{mCuMV}_{T^{-}}$ MERS nanovaccine candidate. The icosahedral $T=3 \mathrm{CuMV}_{\Pi T}$-VLPs are identical to the parent VLPs where subunits $A$ are arranged in pentamers and subunits $\mathrm{B} / \mathrm{C}$ are arranged in hexamers ${ }^{25}$. $\mathrm{CuMV}_{T^{-}}$ VLPs incorporate a tetanus toxin (TT) epitope which is a universal T cell epitope binding to essentially all HLA-DR molecules. The incorporated $\Pi$ epitope is displayed at the interior surface of the particles, allowing the VLPs to self-assemble without altering their icosahedral geometry or interfering with epitopes to be displayed on the exterior surface ${ }^{20,29}$. Furthermore, displaying the $\Pi$ epitope on the interior surface of the particle prevents interference with $\Pi$-specific antibodies. TT-epitope incorporation is believed to improve the immune response specifically in aged people due to enhanced interaction between $\Pi$-specific $T_{H}$ cells and epiotpe specific $B$ cells, and is based on the fact that pre-existing immunity to $\Pi$ epitope is broad in humans due to extensive vaccination programs. We have incorporated the coding sequencine of the receptor-binding motif (RBM; a.a. 484-566) of MERS-CoV protein into $\mathrm{CuMV}_{T T}$ nanoparticles. The RBM domain has been selected based on previous studies on SARS-CoV-2, where RBM proved to be a potent vaccine epitope $\mathrm{e}^{30,31}$.

The vaccine candidate was engineered as a mosaic particle where unmodified wild-type monomers and genetically modified monomers (incorporating RBM) assemble together forming a VLP (Fig. 1a). Purification of $\mathrm{mCUMV}_{T T}-$ MERS was carried out using sucrose gradient (Fig. 1b). The unmofidied monomer has a size of $\sim 28 \mathrm{kD}$ while the ones incorporating RBM have an apparent size of $\sim 42 \mathrm{kDA}$ as shown in SDS-PAGE (Fig. 1c). Furthermore, the production of $\mathrm{mCuMV}_{T}$-MERS in $E$. coli system allowed spontaneous packaging of ssRNA which serve as toll-like receptor (TLR) 7/ 8 agonist. We have also tested the stability of the vaccine candidate and the results indicate that the platform is thermostable at $4^{\circ} \mathrm{C}$ for more than a year and for about a month at RT (Fig. 1d). The size of the engineered $\mathrm{mCuMV}_{\Pi}-\mathrm{MERS}$ particles is $\sim 40-50 \mathrm{~nm}$. Densitometric analysis suggests an approximate $40 \%$ incorporation of RBM. As each VLP contains 180 capsid protein (CP) subunits, $40 \%$ results in $~ 70$ RBM antigen-containing $\mathrm{CuMV}_{\mathrm{T}^{-}}$ CP molecules per 1 VLP (Fig. 1e and Video 1). Dynamic light scattering revealed a homogenous and uniform peak of hydrodynamic radius $\left(R_{H}\right)$ of $\sim 94 \mathrm{~nm}$ (Fig. 1f); the observed peak is larger than the expected size due to water molecules surrounding the VLPs. Electron microscopy imaging confirms the assembly of icosahedral particles and indicated no signs of VLP aggregation following expression in E. coli (Fig. 1g).

\section{RBM displayed on the surface of $\mathrm{MCuMV}_{\mathrm{TT}}-\mathrm{MERS}$ vaccine binds the human receptor DPP4}

To confirm the antigenicity of $\mathrm{mCuMV}_{T}$-MERS as well as the correct folding and confirmation of RBM displayed on the particle's surface, we performed a receptor binding assay. To this end, the human receptor DPP4 was coated on ELISA plate. mCUMV $_{\Pi T}-$ MERS vaccine was added, in parallel to CuMV $_{\Pi T}$ as a control. Anti-CuMV $V_{T}$ antibodies were used as a secondery antibody to detect receptor bound VLPs. The results revealed that $\mathrm{mCuMV}_{\Pi}-\mathrm{MERS}$ can bind to DPP4 receptor indicating correct folding of RBM on the surface of the VLP while the control did not show any binding (Fig. 2).

\section{Vaccination with $\mathrm{mCuMV} \mathrm{TT}_{\mathrm{TT}}$-MERS elicits a strong humoral immune response}

The immunogenicity and the induction of a humoral immune response in murine models upon vaccination with $\mathrm{mCuMV}_{\mathrm{TT}}-\mathrm{MERS}$ was examined by ELISA. BALB/c mice were primed s.c. with $100 \mu \mathrm{g}$ $\mathrm{CuMV}_{T}$ as a control or with $\mathrm{mCuMV}_{T}$-MERS vaccine candidate without any adjuvant. A booster dose was given 28 days later. Mice were bled on a weekly basis and terminally bled on day 49 as illustrated in Fig. 3a. Total lgG was measured against RBD as well as against spike protein of MERS-CoV. RBD-specific IgG antibodies were detected as early as seven days post priming in the group vaccinated with $\mathrm{mCuMV}_{\mathrm{T}}$-MERS. The induced response against RBD increased $\sim 10$-fold following priming and reached the peak one week after the booster dose (Fig. 3b, c). The response against spike protein was somewhat delayed compared to the response against RBD protein. Nevertheless, an $\sim 100$-fold increase in lgG titer was detected three weeks after priming on day 21 and further increased following the booster dose (Fig. 3d, e). No RBD or spike specific antibodies were detected prior to vaccination. 
a.

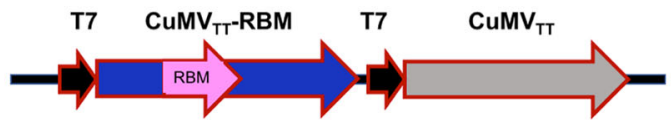

b.

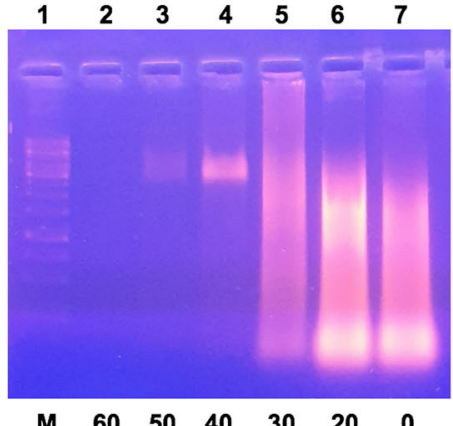

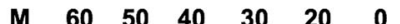

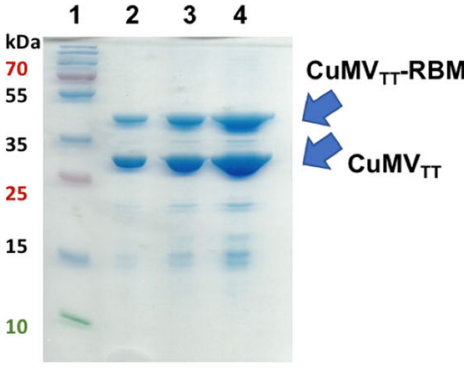

d.

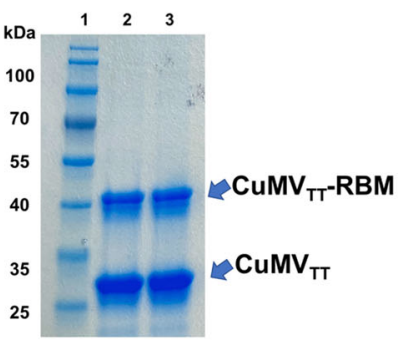

e.

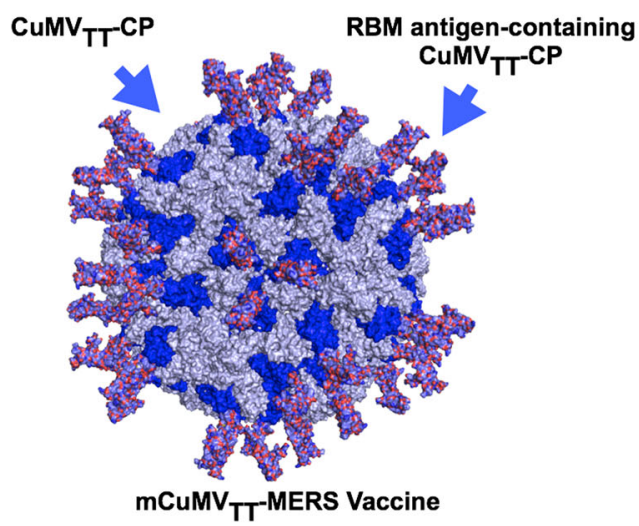

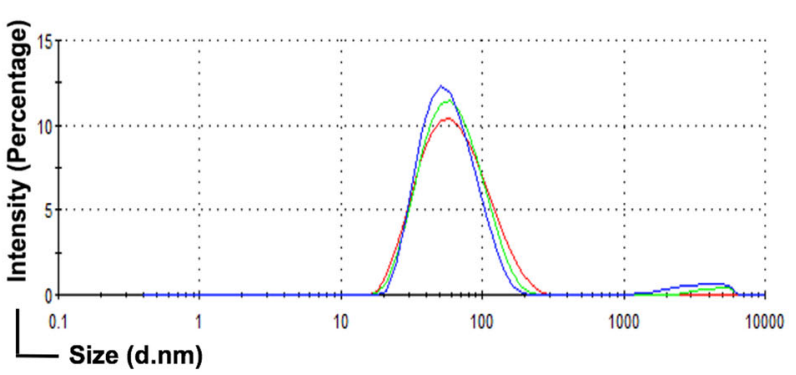

g.

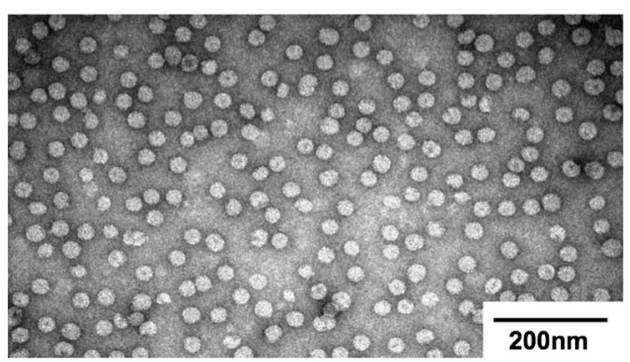

Fig. 1 Efficient incorporation of MERS antigen receptor-binding motif (RBM) into mosaic CuMV TT $^{-V L P s . ~ a ~ G e n e ~ m a p ~ i n ~ p E T D u e t-1 ~ f o r ~}$ expression of a mosaic mCuMV $\mathrm{T}_{T}-\mathrm{MERS}$ vaccine candidate based on self-assembling of unmodified $\left(\mathrm{CuMV}_{\mathrm{TT}}\right)$ and genetically modified monomers displaying RBM (CuMV $\left.{ }_{T T}-\mathrm{RBM}\right)$. b Agarose gel analysis of sucrose gradient fractions, Lane 1: molecular marker, Lanes 2-7: 60 0 sucrose gradient fractions of $\mathrm{mCuMV}_{\mathrm{TT}}$ MERS. Fractions $40 \%$ and $50 \%$ contain VLPs, incorporated host cell ssRNA is stained with ethidium bromide. c SDS-PAGE stained with coomassie blue stain, Lane 1: protein marker, Lanes 2-4: mCuMV $\mathrm{TT}_{\mathrm{TT}} \mathrm{MERS}^{\mathrm{N}}$ vaccine showing a band of unmodified CuMV ${ }_{T T}$ monomer of $\sim 28 \mathrm{kDa}$ and RBM antigen-containing CuMV $\mathrm{TT}_{\mathrm{TT}}$ monomer of $\sim 42 \mathrm{kDa}(2,4$, and $8 \mu \mathrm{g}$ of protein loaded). d SDS-PAGE stained with coomassie blue stain showing the stability of mCuMV TT $^{-M E R S ~ v a c c i n e ~ a f t e r ~} 1$ month in RT, Lane 1: protein marker, Lane 2: $\mathrm{mCuMV}_{\mathrm{TT}}$-MERS vaccine. e 3D model of $\mathrm{mCuMV}_{\mathrm{TT}}-\mathrm{MERS}$ vaccine illustrating unmodified $\mathrm{CuMV}_{\mathrm{TT}}$ monomer (in gray color) and the genetically modified $\mathrm{CuMV}_{\mathrm{TT}}$ monomer (in blue color) displaying RBM (in pink color) and a video (Supplementary Data). $f$ Dynamic light scattering. $\mathbf{g}$ Electron microscopy (EM) of $\mathrm{mCuMV}_{\mathrm{TT}}-\mathrm{MERS}$ vaccine, scale $200 \mathrm{~nm}$.

\section{mCuMV $_{\mathrm{TT}}$-MERS vaccine induces RBD and spike-specific IgG subclasses as well as isotype switching to IgA}

We next evaluated the ability of the engineered vaccine candidate to induce $\lg$ subclasses and $\lg A$ using the sera collected at day 49. To this end, ELISA plates were coated with RBD or spike proteins of MERS-CoV. The results showed that $\mathrm{mCuMV}_{\pi T}-\mathrm{MERS}$ vaccination induces the production of all RBD-specific $\operatorname{lgG}$ subclasses (lgG1, IgG2a, IgG2b and $\lg G 3$ ) dominated by $\lg G 1$ and IgG2a (Fig. 4a, b). IgG subclasses could also be detected against the spike protein as shown in Supplementary Fig. 1. Isotype switching to RBD-specific lgA antibodies was also induced following vaccination with $\mathrm{mCuMV}_{T}-$ MERS (Fig. 4c) and reached an $\mathrm{OD}_{50}$ of greater than 1:100 (Fig. 4d).

\section{Induction of high avidity antibodies after vaccination with mCuMV TT $^{-M E R S}$}

To further characterize the induced RBD-specific IgG antibodies, we performed avidity ELISAs using sera collected one week following the booster dose. The results showed that the $\mathrm{mCMV}_{\mathrm{T}^{-}}$ MERS vaccine is capable of generating high avidity antibodies (Fig. 5a). Essentially no difference was detected between the ELISA plates treated with PBST or 7 M UREA (to eliminate low avidity 


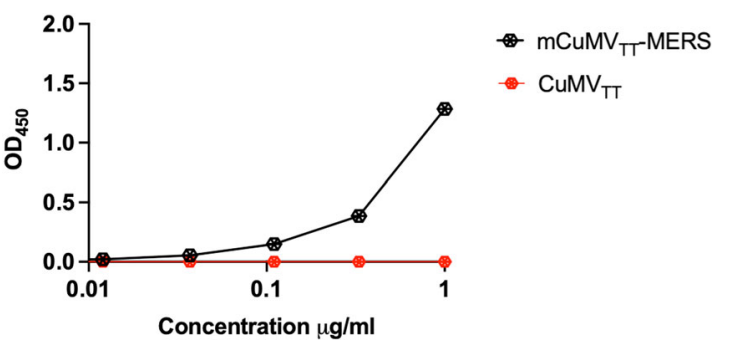

Fig. 2 RBM displayed on the surface of $\mathrm{mCuMV}_{T T}$-MERS vaccine binds human receptor DPP4. DPP4 binding of $\mathrm{MCUMV}_{\mathrm{TT}}-\mathrm{MERS}$ vaccine candidate and $\mathrm{CuMV}_{\mathrm{TT}}$ as a control. Plates coated with $1 \mu \mathrm{g} / \mathrm{ml}$ of DPP4. Binding revealed with an anti-CuMV mAb. One representative of three similar experiments is shown.

antibodies) for the group vaccinated with $\mathrm{mCuMV}_{\Pi T}-\mathrm{MERS}$ (Fig. 5b). We also calculated the avidity index by comparing the two treated plates for the group vaccinated with $\mathrm{mCuMV}_{\Pi \mathrm{T}}$-MERS. The mean index was $\sim 0.6$, indicating that around $60 \%$ of the total IgG antibodies are of high avidit for RBD (Fig. 5c). The avidity of the spike-specific antibodies was also tested (Fig. 5d). The small difference $(p$. 0.0327) detected between the sera treated with PBST or Urea indicate that about $30 \%$ of the generated antibodies could recognize the spike protein with high avidity (Fig. 5e, f).

\section{mCUMV $_{T T}$-MERS-induced antibodies block binding of RBD to the viral receptor DPP4 and neutralize the wild-type MERS virus}

To determine whether the induced IgG antibodies can compete with the human receptor DPP4 for binding to RBD, we performed antibody competition assays using biolayer interferometry. RBDHis was immobilized onto anti-His biosensors and competitions of DPP4 to RBD was quantified as reduction in RBD binding in the presence of serum samples. As shown in Fig. 6a, sera of mice immunized with $\mathrm{mCuMV}_{T}$-MERS were able to inhibit DPP4 binding to RBD. For comparison, sera from control mice immunized with $\mathrm{CuMV}_{\Pi}$ alone were used. The results indicate that immunization with $\mathrm{mCuMV}_{T}-\mathrm{MERS}$ induced anti-RBM antibodies capable of inhibiting the binding of MERS-RBD to DPP4.

To determine the neutralizing capacity of the induced antibodies, the sera were tested for their ability to prevent cytopathic effects of MERS-CoV/EMC/2012 on Vero cells in vitro (CPE-based neutralization assay). The titer is indicated as the dilution at which an inhibiting effect was visible and the cytopathic effect was fully prevented. The group vaccinated with mCuMV $_{T_{T}}$-MERS fully inhibited the cytopathic effect of the virus while the control group $\mathrm{CuMV}_{T}$ did not show any inhibition, demonstrating a strong neutralizing capacity of the induced antibodies (Fig. 6b).

\section{DISCUSSION}

Few MERS-CoV vaccines based on VLPs have been reported so far in preclinical studies. Wang et al. have developed a chimeric VLP vaccine expressing RBD of MERS-CoV utilizing canine parvovirus (VP2). The vaccine could induce a good response in murine models when delivered with Poly $(I: C)^{12}$. The same group has tested another VLP vaccine containing MERS-CoV S, E and M proteins in rhesus macaques which also showed efficacy ${ }^{32}$.

In the present study, we have engineered a vaccine candidate against MERS-CoV by genetically fusing the RBM domain of MERS$\mathrm{CoV}$ into our immunologically optimized VLP-platform derived from the cucumber-mosaic virus $\left(\mathrm{CuMV}_{\Pi}\right.$-VLPs). Designing the vaccine-candidate in this study as a mosaic vaccine was an essential step to allow the formation of icosahedral $T=3 \mathrm{VLPs}^{25}$. Each engineered VLP incorporates $\sim 70$ RBM fused to the CP (40\%).
Expression in E. coli facilitateted the packaging of bacterial ssRNA which serves as TLR7/8 ligand. Previous studies demonstrated that VLP-based vaccines are capable of inducing IL-21-independent secondery plasma cells only in the presence of TLR7/8 agonists (ssRNA). Consequently, high levels of IgG antibodies with high affinity are produced within few days after challenge ${ }^{22,33}$. ssRNA packaged in VLPs polarizes the induced immune response towards $T_{H} 1$ rather than $T_{H} 2$, which prevents enhanced disease after viral challenge at least in preclinical models ${ }^{2}$. In addition, we incorporated a tetanus toxin (TT) epitope in the interior surface of our CUMV $\mathrm{C}_{\Pi}-\mathrm{VLPs}$. This may not necessarily affect the antibody response in mice or dromedaries as they are not pre-immunized against $T$. However, the immunogenicity will be enhanced in humans due to previous tetanus vaccinations, likely helpful in elderly people and immunodeficient individuals who are known to require more immunogenic vaccines as compared to the general population. We have chosen the RBM-MERS as our vaccine target based on several grounds: (1) we found that genetically fusing the whole RBD domain of SARS-CoV-2 into VLPs hinders the assembly process of VLPs; on the other hand fusing RBM in AP205-VLPs resulted in an effective vaccine capable of neutralizing SARS-CoV$2^{31}$. (2) Based on previous studies for SARS-CoV-1 and 2, RBD is glycosyated and methylated. Such posttranslational modifications may be difficult to reproduce in bacteria and may result in the induction of low affinity, poorly protective antibodies. Importantly, RBM is neither glycosylated nor methylated and thus can directly interact with the human receptor MERS-DPP4. RBM is also the major target of neutralizing antibodies ${ }^{34,35}$ and therefore represents and ideal vaccine target. To our knowledge, we present here the first VLP-based vaccine displaying the RBM domain of MERS$\mathrm{CoV}$ that can easily be produced in large amounts as it selfassembles in $E$. coli without the need of any further modifications.

Vaccine candidates should display antigens in an authentic native configuration in order to induce an effective $B$ cell response $^{18}$. Using Sandwich ELISAs, we have shown that $\mathrm{mCUMV}_{T}-\mathrm{MERS}$ particles are able to detect and bind to the viral receptor DPP4. This confirms that the MERS RBM displayed and fused to the VLP, has the correct conformation which is important for the induction of the appropriate neutralizing antibody response.

We have not directly measured the induction of $T_{H}$ cells responses by our vaccine candidate, mostly because the expected effector mechanism is induction of neutralizing antibodies. In addition, the size of the RBM-domain may be too small to reliably induce a $T_{H}$ cell response in inbred mice. However, we have previously shown that VLP-specific $T_{H}$ cell responses mediate isotype-switch for $B$ cells specific for antigens displayed on the VLPs. Furthermore, the bacterial RNA packaged in VLPS, such as $\mathrm{CuMV}_{\Pi \text {, }}$, drive $\mathrm{CD8}^{+}$and $\mathrm{T}_{\mathrm{H}} 1$ responses.(44-46).

Mouse lgG antibodies vary in their immunological, biochemical as well as physiological properties. We have previously shown that TLR7/8 triggering in B cells induces subclass switch to lgG2a and lgG2b; bacterial RNA was most efficient at triggering such responses ${ }^{23,36}$. Vaccination with $\mathrm{mCuMV}_{T}$-MERS enhanced the induction of all lgG subclasses which was dominated by $\operatorname{lgG} 1$ and $\operatorname{lgG} 2 \mathrm{a}$, other subclasses could also be detected to a much lesser extent. In addition, RNA loaded VLPs may also induce IgA responses, again in a TLR7/8 dependent manner ${ }^{22,24}$. This appears particularly important for MERS-CoV and other respiratory diseases-causing viruses, such as SARS-CoV- 1 and -2 , as $\lg A$ may be able to neutralize the virus locally in the lung without causing inflammation, a feature that may be particularly critical in patients with high viral load. IgA is the predominant lg isotype in the mucosal tissue and has a very important role in the defense against respiratory infections ${ }^{37}$. Thus, an effective vaccine against respiratory viruses should induce $\lg A$ antibodies. It is therefore of key importance that our newly developed vaccine is able to induce a significant increase in serum IgA levels. Whether the 
a.

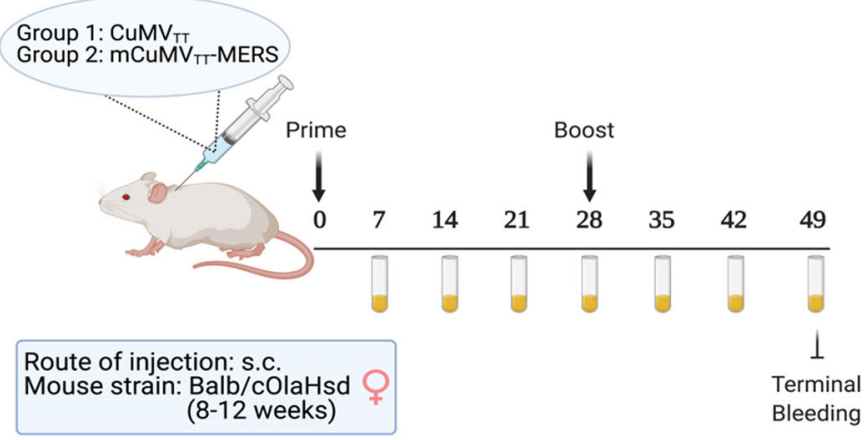

b.

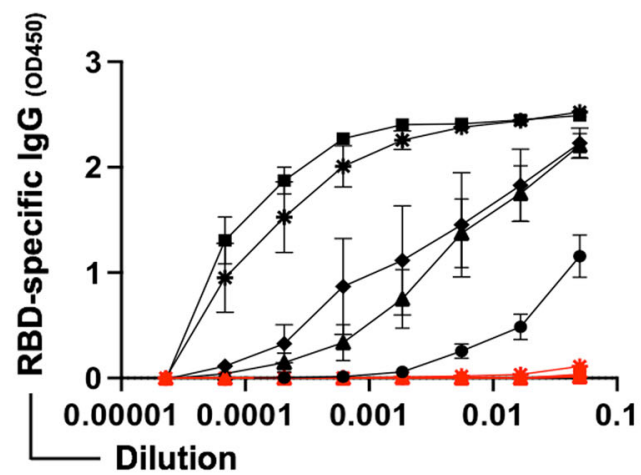

d.

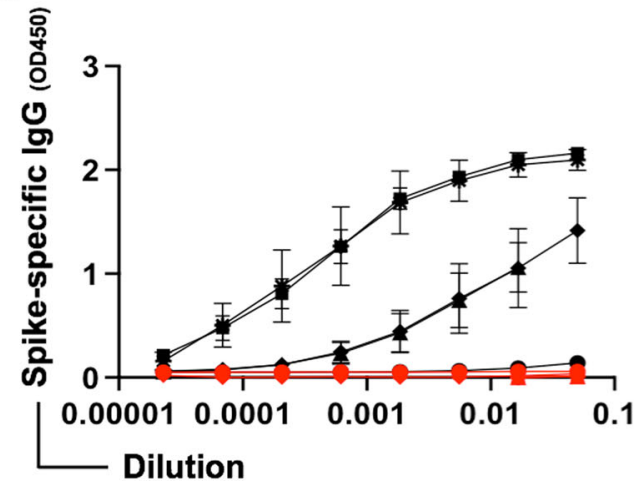

- D7 CuMV

- D14 CuMV

- D21 CuMV

- D35 CuMV

- D49 CuMV

- D7 mCUMV TTMERS

- D14 mCuMV TT-MERS

- D21 mCUMV TT-MERS

- D35 mCuMV TrMeRS

*- D49 mCuMV ${ }_{\text {TT}}$ MERS

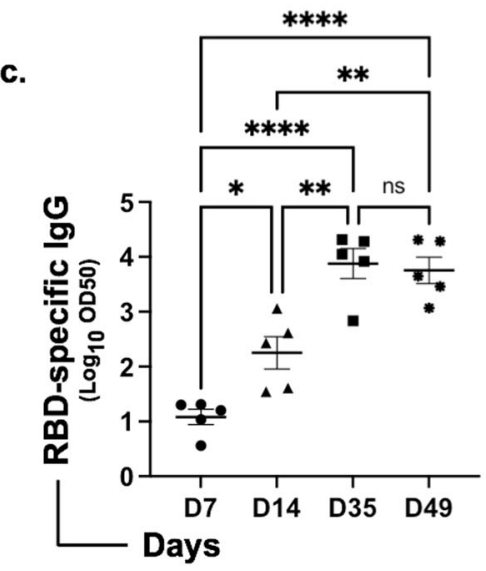

e.

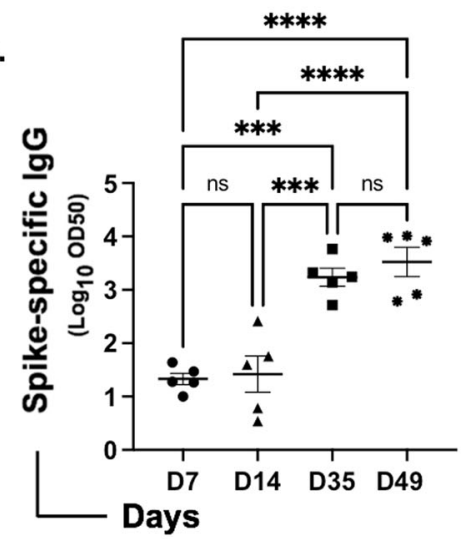

Fig. 3 Vaccination with $\mathbf{m C u M V} \mathbf{T T}_{\mathrm{T}}-\mathrm{MERS}$ elicits a strong humoral immune response. a Overview of vaccination regimen (prime on day 0 and boost on day 28), bleeding time points and groups. Serum samples were collected from mice on a weekly basis. Figure created with BioRender.com. b RBD-specific lgG titer for the groups vaccinated with CuMV $\mathrm{TT}_{\mathrm{TT}}$ control or $\mathrm{mCuMV}_{\mathrm{TT}}-\mathrm{MERS}_{\mathrm{S}}$ on days 7, 14, 21, 35, and 49 measured with $\mathrm{OD}_{450 \mathrm{~nm}} \cdot \mathbf{c} \mathrm{Log}_{10} \mathrm{OD}_{50}$ values (mean $\pm \mathrm{SEM}$ ) of RBD-specific IgG titer for the groups vaccinated with $\mathrm{mCuMV}$ (TTERS on days 7,14, 35, and 49 (data from B). d Spike-specific IgG titer for the groups vaccinated with CuMV $\mathrm{TT}_{\mathrm{TT}}$ or mCuMV TT-MERS on days 7,14,21,35, and 49 measured with $\mathrm{OD}_{450}$. e $\log _{10} \mathrm{OD}_{50}$ values (mean $\pm \mathrm{SEM}$ ) of spike-specific IgG titer for the groups vaccinated with $\mathrm{mCuMV} \mathrm{T}_{\mathrm{TT}}-\mathrm{MERS}$ on days $7,14,35$, and 49 (data from D). Statistical analysis using one-way ANOVA. Control group $n=5$ and vaccine group $n=5$. One representative of 2 similar experiments is shown. The value of $p<0.05$ was considered statistically significant $\left({ }^{*} p<0.01,{ }^{* *} p<0.001,{ }^{* * *} p<0.0001\right)$.

increased serum IgA levels in mice can translate to correspondingly high IgA levels in humans and the mucosa needs to be confirmed.

Testing the quality of the RBD-specific antibodies has shown high avidity binding which is a critical parameter for an effective vaccine. UREA is interfering with the antibody-antigen binding by breaking up the hydrophobic bonds. We found that $\sim 60 \%$ of the RBD specific IgG antibodies are of high avidity and bind strongly to its antigen even in the presence of UREA. Thus, RBM displayed on $\mathrm{CuMV}_{T}$ induces high avidity antibodies.

The main goal for any anti-viral vaccine is the elicitation of neutralizing antibodies which are able to directly inhibit cellular infection and provide protection from disease ${ }^{38}$. For MERS-CoV, most neutralizing antibodies bind to the spike glycoprotein and inhibit viral attachement to the human receptor DPP4, hence blocking viral entry and intracellular replication. Our test sera were 
a.

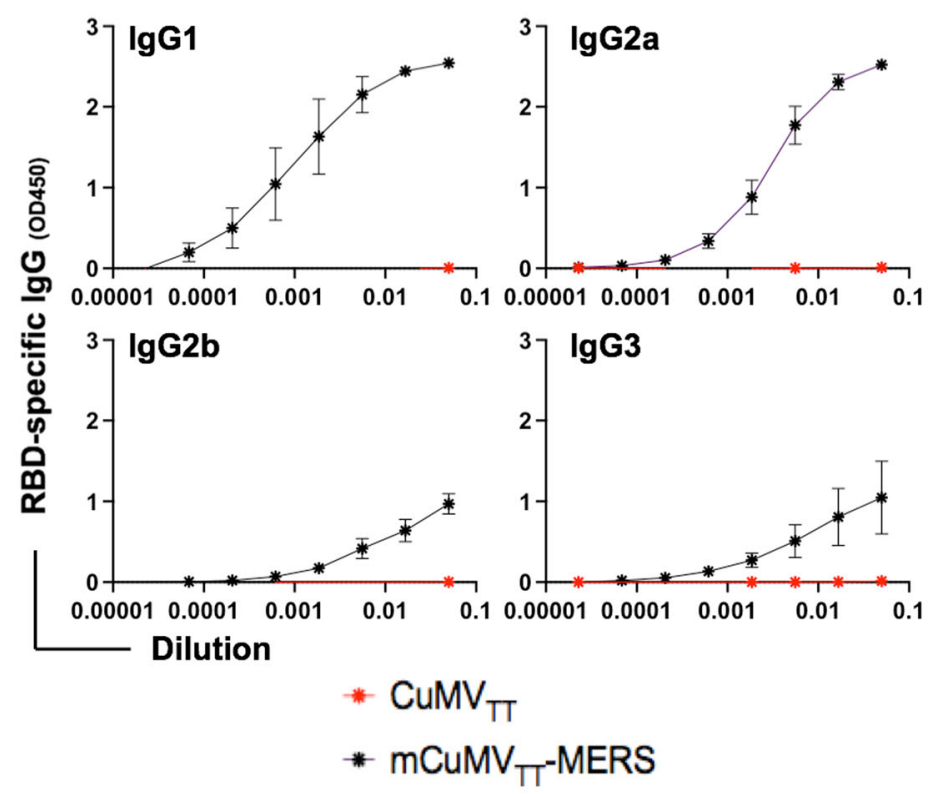

C.

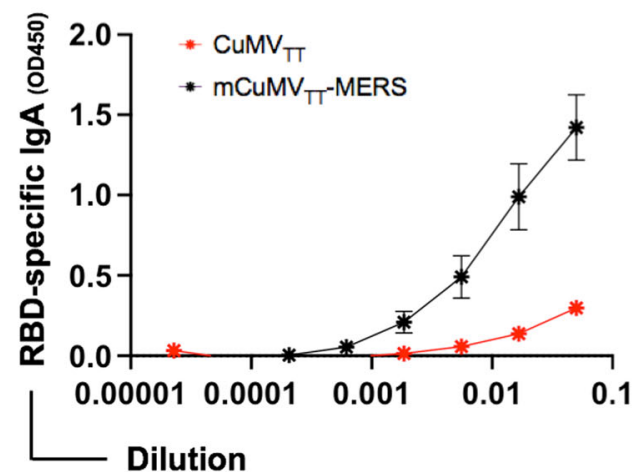

b.

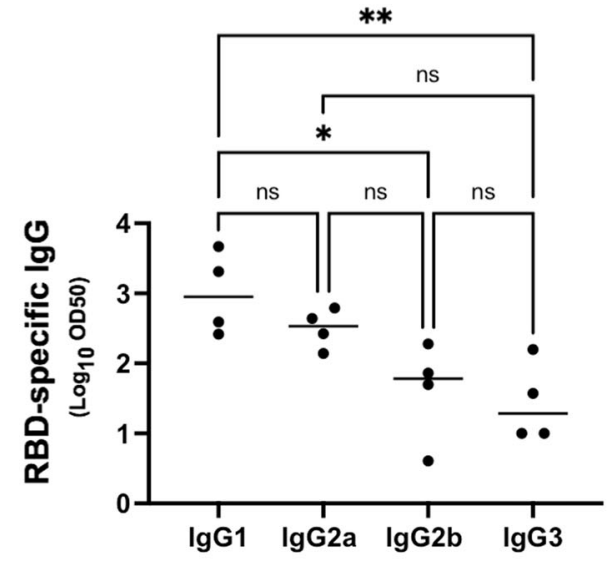

d.

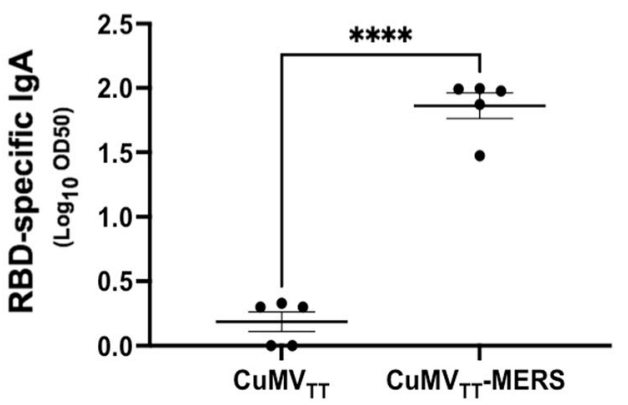

Fig. $4 \mathrm{mCuMV}_{\mathrm{TT}}$-MERS vaccine induces RBD and spike-specific IgG subclasses as well as isotype switching to IgA. a RBD-specific IgG1, IgG2a, lgG2b and IgG3 titers for the groups vaccinated with CuMV

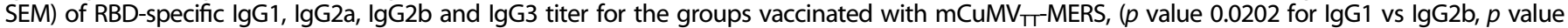
0.0096 for lgG1 vs lgG3). Statistical analysis using One-way ANOVA. Control group $n=4$ and vaccine group $n=4$. c RBD-specific lgA titer for the

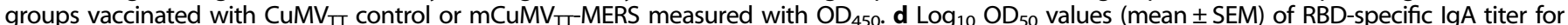
both groups, ( $p$ value $<0.0001$ ). Statistical analysis using Student's $t$ test. Control group $n=5$ and vaccine group $n=5$. One representative of two similar experiments is shown. The value of $p<0.05$ was considered statistically significant $\left({ }^{*} p<0.01,{ }^{* *} p<0.001,{ }^{* * *} p<0.0001\right)$.

probed for their ability to inhibit the cytopathic effect of MERSCoV/EMC/2012 isolate on Vero cells. Indeed, sera from vaccinated mice were able to fully neutralize viral replication, showing that the vaccine is able to induce protective antibodies which can shield the host's cells from MERS-CoV infection.

Collectively, we have shown in this study that an engineered VLP-based vaccine can efficiently induce high specific anti-RBD and spike antibodies that effectively neutalize MERS-CoV. As MERS represents an immanent global threat to human health, it seems rational to further develop this vaccine candidate and make it availalbe for emergency use.

\section{METHODS}

$\mathrm{mCuMV}_{\mathrm{TT}}$-MERS vaccine candidate production, purification and analysis

E. coli C2566 cells were transformed with the pETDu-CMVB3d-MERS-M$\mathrm{CMV}_{T}$ plasmid containing RBM of MERS and the Ampicillin (Amp) resistance gene. After transformation, five individual colonies were inoculated in $4 \mathrm{ml} 2 \mathrm{TY}(1.6 \%$ Trypton, $1.0 \%$ Yeast extract, $0.5 \% \mathrm{NaCl})$ with Amp $(100 \mathrm{mg} / \mathrm{l})$ and $0.1 \%$ glucose and cultured overnight at $37{ }^{\circ} \mathrm{C}$ without shaking. The next day, $1 \mathrm{ml}$ of the starting culture was added to $20 \mathrm{ml} 2 \mathrm{TY}$, cultivated at $30^{\circ} \mathrm{C}$ until an $\mathrm{OD}_{600 \mathrm{~nm}}$ of 0.8 was reached and then induced with $0.2 \mathrm{mM}$ IPTG and $5 \mathrm{mM} \mathrm{MgCl}$ and cultivated $\mathrm{ON}$ at $20^{\circ} \mathrm{C}$ and $7 \mathrm{xg}$. After $18 \mathrm{~h}$ an $\mathrm{OD}_{600 \mathrm{n}} \mathrm{m}$ of 5.20 was reached and samples for SDS-PAGE were prepared. After SDS-PAGE analysis of individual clones the $520 \mathrm{ml}$ cultures were pooled together $(100 \mathrm{ml}$ in total) and the biomass was collected by centrifugation. The pellet was frozen at $-20^{\circ} \mathrm{C}$. To disrupt the cells, $10 \mathrm{ml}$ of buffer ( $20 \mathrm{mM}$ Tris, $5 \mathrm{mM}$ EDTA, $5 \mathrm{mM}$ Et-SH, $5 \%$ glycerol, $10 \%$ sucrose, $\mathrm{pH} 8.0$ ) was added to resuspend and further treat the biomass with ultrasound (Hielscher 200 , power $70 \%$, pulse $50 \%, 16 \mathrm{~min}$ ) on ice. Then, $0.5 \%$ TX-100 was added and the solution was rotated at $10 \mathrm{rpm}$ overnight (ON) at $4{ }^{\circ} \mathrm{C}$ without centrifugation. The solution was then centrifugated for $10 \mathrm{~min}$ at 15,557 xg (Eppendorf 5804) and the pellet was discarded. The soluble fraction was loaded on the top of the sucrose gradient (20-60\%; in buffer containing $20 \mathrm{mM}$ Tris, $2 \mathrm{mM}$ EDTA, 5\% glycerol, $0.5 \% \mathrm{TX}-100, \mathrm{pH} 8.0$ ) and centrifugated in Beckman SW32 rotor for $6 \mathrm{~h}$ at $106,559 \mathrm{xg}$ at $18^{\circ} \mathrm{C}$. The gradient fractions $(6 \mathrm{ml})$ were then 
a.

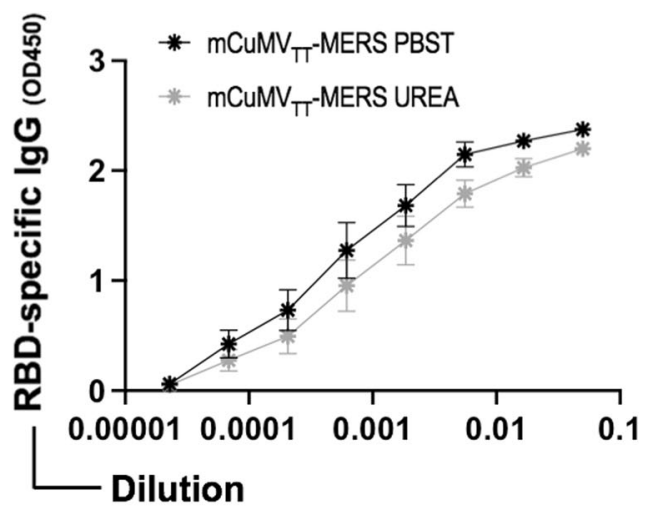

d.

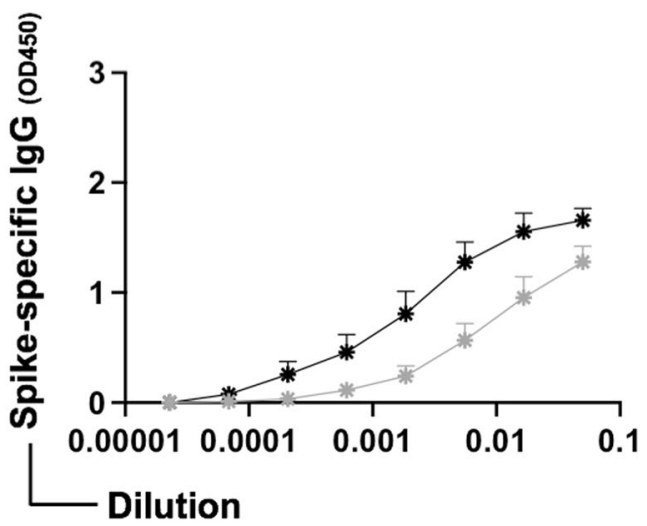

b.

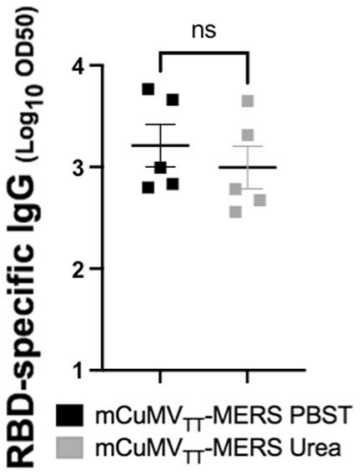

e.

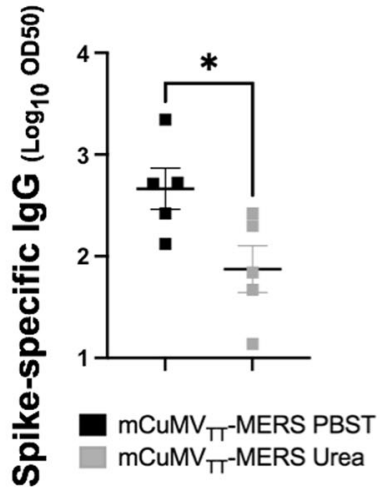

c.

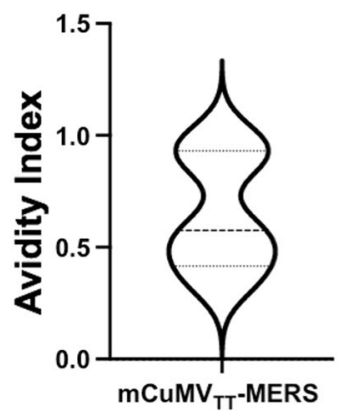

f.

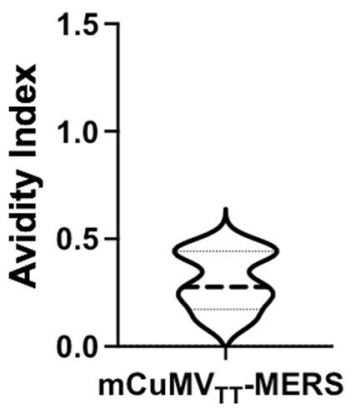

Fig. 5 Induction of high avidity antibodies after vaccination with mCuMV $_{\mathrm{TT}}-\mathrm{MERS}$. $\mathbf{a}$, $\mathbf{d}$ RBD- and spike specific IgG titer for the group vaccinated with $\mathrm{mCuMV}_{\mathrm{TT}}$-MERS vaccine on day 35 measured with $\mathrm{OD}_{450}$. After serum incubation one plate was treated with $\mathrm{PBS}+0.05 \%$ Tween 20 and the other plate with $7 \mathrm{M}$ Urea in PBS $+0.05 \%$ Tween $20 . \mathbf{b}$, e $\log _{10} \mathrm{OD}_{50}$ values (mean \pm SEM) of RBD- and spike-specific lgG titers (shown in a and $\mathbf{d}$ ) for the group vaccinated with $\mathrm{mCuMV}_{\mathrm{TT}}-\mathrm{MERS}$, ( $p$ value 0.4860 in $\mathbf{b}$ and 0.0327 in e). $\mathbf{c}$, $\mathbf{f}$ Avidity index showing the percentage of high avidity RBD- and spike-specific lgG antibodies calculated with the data from (a) or (d). Statistical analysis using Student's $t$ test. Control group $n=5$ and vaccine group $n=5$. One representative of 2 similar experiments is shown. The value of $p<0.05$ was considered statistically significant $\left({ }^{*} p<0.01,{ }^{* *} p<0.001,{ }^{* *} p<0.0001\right)$.

removed from the bottom of the $38 \mathrm{ml}$ tube. The $\mathrm{mCuMV}_{\pi T}-\mathrm{MERS}$ containing fraction (40 and $50 \%$ sucrose, pooled) was diluted 1:1 with buffer (20 mM Tris, $2 \mathrm{mM}$ EDTA, 5\% glycerol, $\mathrm{pH}$ 8.0). The VLPs were sedimented using Type 70 rotor (Beckman, $183,960 \times \mathrm{xg}, 4 \mathrm{~h}, 4^{\circ} \mathrm{C}$ ). Then the pellet was dissolved ON in $2 \mathrm{ml}$ of $20 \mathrm{mM}$ Tris, $2 \mathrm{mM}$ EDTA at $4{ }^{\circ} \mathrm{C}$. The solution was clarified by centrifugation ( $5 \mathrm{~min}, 16,873 \mathrm{xg}$ ), the clarified solution overlaid on top of the $30 \%$ sucrose "cushion" solution in $20 \mathrm{mM}$ Tris, 2 mM EDTA, 0.5\% TX-100, pH 8.0 The VLPs were sedimented using Beckman TLA100.3 rotor $\left(220,050 \mathrm{xg}, 60 \mathrm{~min}, 4^{\circ} \mathrm{C}\right)$. The pellet was solubilized in $1 \mathrm{ml}$ of $20 \mathrm{mM}$ Tris, $2 \mathrm{mM}$ EDTA and clarified again by centrifugation ( $5 \mathrm{~min}, 16,873 \mathrm{xg}$ ). Obtained VLPs were characterized using SDS-PAGE, agarose gel, electron microscopy and dynamic light scattering. Protein concentration was determined using BCA test.

\section{Binding ELISA assay}

To test if the vaccine can bind the relevant human receptor DPP4, the plates were coated with $1 \mu \mathrm{g} / \mathrm{ml}$ of DPP4 in PBS at a volume of $50 \mu \mathrm{l} / \mathrm{well}$. The plate was incubated at $4{ }^{\circ} \mathrm{C}$ overnight. The plate was washed with PBS+Tween $0.01 \%$. $50 \mu \mathrm{l} /$ well of Superblock solution (Thermo Fisher, 37518) was added and the plate was incubated for $1 \mathrm{~h}$ at RT on a shaker. The blocking solution was flicked off and $50 \mu \mathrm{l}$ of $\mathrm{mCuMV}_{T}-\mathrm{MERS}$ or $\mathrm{CuMV}_{T}$ (control) from $1 \mu \mathrm{g} / \mathrm{ml}$ was added to the first row of the plate followed by $1: 3$ dilution. The plate was incubated for $1 \mathrm{~h}$ at RT then washed with PBS+Tween $0.01 \%$. Next, $50 \mu \mathrm{l}$ of mouse anti-CuMV ${ }_{T}$ monoclonal antibody (clone 1-1 A8/ batch 2) at a concentration of $1 \mu \mathrm{g} / \mathrm{ml}$ was added to each well as a secondary antibody and incubated for $1 \mathrm{~h}$ at RT on a shaker. The plate was washed and $50 \mu$ of the detection antibody; HRP labeled goat anti-mouse IgG Fc gamma at a dilution of 1:1000 in PBS-Casein $0.15 \%$ was added to each well. The plate was incubated for $1 \mathrm{~h}$ at RT. The plate was developed and OD450 reading was performed (BioTek, USA).

\section{Mice}

Wild type Balb/cOlaHsd mice were purchased from Harlan. All in vivo experiments were performed using 8-12 weeks old female mice.

\section{Ethical approval}

All animal procedures were conducted in accordance with the Swiss Animal Act (455.109.1 - September 2008, 5th) using License No. BE70/ 2018.

\section{Vaccination regimen}

Wild type Balb/cOlaHsd mice (8-12 weeks, Harlan) were vaccinated subcutaneously (s.c.) in the neck with $100 \mu \mathrm{g}$ with either $\mathrm{mCuMV}_{\text {TT}}-\mathrm{MERS}$ vaccine or $\mathrm{CuMV}_{\Pi \text { T }}$ as a control in a volume of $100 \mu \mathrm{l}$ without any adjuvants. The mice received a boost with an equal dose at day 28 and were terminally bled at day 56 . Serum was collected on a weekly basis vial tail bleeding and the serum was isolated using Microtainer Tube (BD Biosciences, USA). 
A.

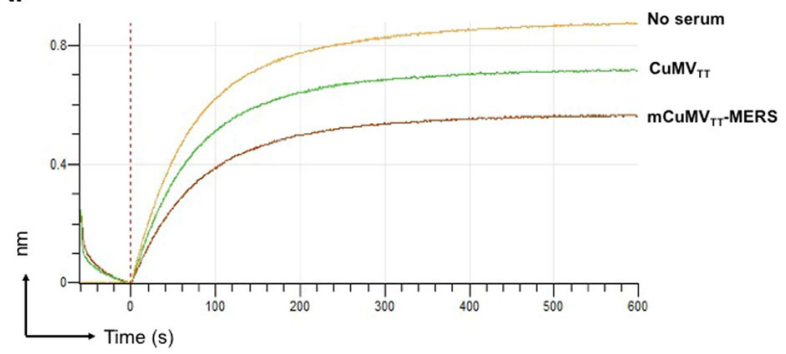

B.

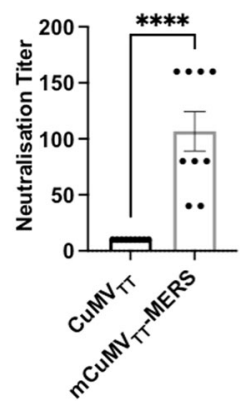

Fig. $6 \mathrm{mCuMV}_{\mathrm{TT}}$-MERS blocks binding to RBD to the viral receptor DPP4 and neutralizes wild-type MERS virus. a BLI-evaluation of DPP4 binding to RBD in the presence of vaccinated mice sera. Binding of DPP4 to BLI biosensors coated with RBD-his tag is significantly reduced in the presence of mouse sera (1:10 dilution, d35) after 2 nd vaccination with CuMV $_{\mathrm{TT}}$-MERS (brown line) than with $\mathrm{CuMV}_{\mathrm{TT}}$ control (green line) or with no serum (line orange) consistent with DPP4-blocking activity. b Neutralization titers (CPE) of the groups vaccinated with $\mathrm{CuMV}_{\mathrm{TT}}$ control and $\mathrm{mCuMV}_{\mathrm{TT}}-\mathrm{MERS}$, $p<0.0001$. Statistical analysis using Student's $t$ test. Control group $n=10$ and vaccine group $n=9$. One representative of two similar experiments is shown. The value of $p<0.05$ was considered statistically significant $\left({ }^{*} p<0.01,{ }^{* *} p<0.001,{ }^{* * *} p<0.0001\right)$.

\section{ELISA (Enzyme-Linked Immunosorbent Assay)}

To determine the total lgG antibody titers, ELISA Corning ${ }^{\mathrm{TM}}$ 96-Well Half-Area Plates (Fisher Scientific, USA) were coated with $1 \mu \mathrm{g} / \mathrm{ml}$ MERS-CoV RBD, (a.a. 367-606) (Sino Biological, USA) or MERS-CoV Spike/S1 protein S1 Subunit, (a.a. $1-725)$, diluted in PBS in a volume of $50 \mu \mathrm{l} /$ well. The plates were incubated overnight at $4{ }^{\circ} \mathrm{C}$ on a shaker. The next day the plates were washed with the ELISA washer (BioTek, 405 TS) with PBS-tween $0.01 \%$. The plates were blocked using $100 \mu \mathrm{l} /$ well PBS-Casein $0.15 \%$ and incubated at RT for $2 \mathrm{~h}$ on a shaker. The blocking solution was removed by flicking the plates. Serum samples were diluted 1:20 followed by 1:3 serial dilution except for the last row which was used as a negative control. The plates were incubated for $2 \mathrm{~h}$ at RT on the shaker. Plates were washed with PBS-tween $0.01 \%$ and secondary anti mouse IgG Fc gamma conjugated with Horse-Radish Peroxidase (Jackson Immunoresearch Cat. Nr. C840T69) (1:1000) was added $50 \mu \mathrm{l} /$ well. The plates were incubated for another $1 \mathrm{~h}$ on a shaker, then washed and developed and OD450 reading was performed (BioTek, USA). $\log _{10} \mathrm{OD}_{50}$ values were calculated using GraphPad PRISM.

To assess the subclass antibody response, the same procedure was performed, except using a different secondary antibody equivalent to each subclass: Rat anti-mouse IgG1 (BD Pharmingen, Cat. 559628, 1:2000 dilution), biotinylated mouse anti-mouse IgG2a (Clone 8.3, BD Biosciences, USA, 1:1000 dilution), goat anti-mouse lgG2b (Invitrogen, Ref. M32407, 1:2000 dilution) and goat anti-mouse lgG3 (Southern BioTech, Cat No 1101-05, 1:4000 dilution).

To detect IgA antibodies the plates were coated with $1 \mu \mathrm{g} / \mathrm{ml}$ MERS-CoV RBD, (a.a. 367-606) (Sino Biological, USA) and goat anti-mouse IgA POX (ICN 55549, ID 91, 1:1000 dilution) was used as a secondary antibody. An additional step prior to serum incubation in order to deplete $\lg \mathrm{G}$ was performed. $10 \mu$ l of Protein G beads (Invitrogen, USA) were transferred into a tube and placed into a magnet. The liquid was removed and $75.6 \mu \mathrm{l}$ diluted sera in PBS-Casein $0.15 \%$ was added to the beads and mixed. The tube was incubated on a rotator at RT for $10 \mathrm{~min}$. The tubes were placed back into the magnet and ELISA was carried out as described above.

\section{Avidity ELISA}

To determine the avidity of IgG antibodies, two sets of plates were prepared. Both were coated with $1 \mu \mathrm{g} / \mathrm{ml}$ MERS-CoV RBD, (a.a. 367-606) (Sino Biological, USA). After serum incubation, one set of plates was washed three times for $5 \mathrm{~min}$ with $50 \mu \mathrm{l} /$ well $7 \mathrm{M}$ Urea in PBS $+0.05 \%$ Tween 20 whereas the other set was washed with the same amount of PBS $+0.05 \%$ Tween. In-between the washing steps, all the plates were washed with PBS $+0.01 \%$ Tween 20 with the ELISA washer. The rest of the procedure is identical as described above.

\section{Competition assay (OCTET)}

The antibody competitive binding activities of the induced antibodies was performed on an OCTET RED96e (Fortébio) instrument which allows real-time analysis due to the shift in the wavelength of the reflected light. Anti-PentaHIS (HIS1K, Lot 2006292, FortéBio) biosensors were first loaded into biosensor microplates and pre-hydrated in BLI assay buffer (PBS, 0.1\% BSA, 0.02\% Tween 20) for $10 \mathrm{~min}$. 96-well microplates were loaded with $200 \mathrm{ml}$ per well. The assay plate was then prepared as follows: column 1 (BLI assay buffer), column $2(15 \mu \mathrm{g} / \mathrm{ml}$ MERS-CoV spike protein fragment RBD, aa267-606, diluted in $200 \mu \mathrm{l} \mathrm{BLI}$ assay buffer) (Sino Biological, USA), column 3 (BLI assay buffer), column 4 (pooled sera from 5 mice diluted 1:10 in BLI assay buffer, samples from control mice vaccinated with $\mathrm{CuMV}_{T}$ VLPs alone and mice vaccinated with $\mathrm{mCuMV}_{T \mathrm{~T}} \mathrm{MERS}$ were used, two additional biosensors were used as control, one for baseline and one without serum sample), column 5 (BLI assay buffer), column 6 ( $50 \mathrm{nM}$ of human receptor DPP4 (Sino Biological, USA) diluted in BLI assay buffer), column 11 (Regeneration buffer, $0.1 \mathrm{M}$ glycine, $\mathrm{pH}$ 1.5) and column 12 (neutralization buffer, BLI assay buffer).

\section{Neutralization assay (cytopathic effect-based neutralization assay)}

Serum samples from day 56 were heat-inactivated for $30 \mathrm{~min}$ at $56^{\circ} \mathrm{C}$. Subsequently, serum samples were diluted two-fold, started at 1:20 to 1:160. Then 100 TCID50 of MERS-CoV/EMC/2012 was added to each well and incubated at $37^{\circ} \mathrm{C}$ for $1 \mathrm{~h}$. Following incubation, the mixtures were added on a monolayer of Vero cells and incubated at $37^{\circ} \mathrm{C}$ for an additional four days. After four days wells were inspected for presence of cytopathic effect (CPE). Titer is expressed as the highest serum dilution that fully inhibits formation of $\mathrm{CPE}$.

\section{Statistical analysis}

Data were analyzed and presented as (mean \pm SEM) using Student's $t$ test or One-way ANOVA as mentioned in the figure legends, with GraphPad PRISM 9. The value of $p<0.05$ was considered statistically significant $\left({ }^{*} p<\right.$ $\left.0.01,{ }^{* *} p<0.001,{ }^{* * *} p<0.0001\right)$.

\section{Reporting summary}

Further information on research design is available in the Nature Research Reporting Summary linked to this article.

\section{DATA AVAILABILITY}

The datasets generated during and/or analyzed during the current study are available from the corresponding author on reasonable request.

Received: 22 February 2021; Accepted: 16 July 2021; Published online: 24 August 2021

\section{REFERENCES}

1. de Wit, E., van Doremalen, N., Falzarano, D. \& Munster, V. J. SARS and MERS: recent insights into emerging coronaviruses. Nat. Rev. Microbiol. 14, 523-534 (2016).

2. Speiser, D. E. \& Bachmann, M. F. COVID-19: Mechanisms of vaccination and immunity. Vaccines (Basel). 8, 404 (2020).

3. Organization WH. WHO MERS Global Summary and Assessment of Risk. (World Health Organization, Geneva, Switzerland, 2019). July, 2019. Contract No.: WHO/ MERS/RA/19.1.

4. Elhazmi, A. et al. Severe acute respiratory syndrome coronavirus 2 (SARS-CoV-2) and Middle East Respiratory Syndrome Coronavirus (MERS-CoV) coinfection: A unique case series. Travel Med Infect. Dis. 41, 102026 (2021). 
5. Tai, W. et al. Recombinant receptor-binding domains of multiple middle east respiratory syndrome coronaviruses (MERS-CoVs) induce cross-neutralizing antibodies against divergent human and camel MERS-CoVs and Antibody Escape Mutants. J. Virol. 91, e01651-16 (2017).

6. Durai, P., Batool, M., Shah, M. \& Choi, S. Middle East respiratory syndrome coronavirus: transmission, virology and therapeutic targeting to aid in outbreak control. Exp. Mol. Med. 47, e181 (2015).

7. Skariyachan, S., Challapilli, S. B., Packirisamy, S., Kumargowda, S. T. \& Sridhar, V. S. Recent aspects on the pathogenesis mechanism, animal models and novel therapeutic interventions for middle east respiratory syndrome coronavirus infections. Front Microbiol. 10, 569 (2019).

8. Alharbi N. K. Vaccines against Middle East respiratory syndrome coronavirus for humans and camels. Rev Med Virol. 2017;27.

9. Muthumani, K. et al. A synthetic consensus anti-spike protein DNA vaccine induces protective immunity against Middle East respiratory syndrome coronavirus in nonhuman primates. Sci. Transl. Med. 7, 301 ra132 (2015).

10. Song, F. et al. Middle East respiratory syndrome coronavirus spike protein delivered by modified vaccinia virus Ankara efficiently induces virus-neutralizing antibodies. J. Virol. 87, 11950-11954 (2013).

11. Kim, E. et al. Immunogenicity of an adenoviral-based Middle East Respiratory Syndrome coronavirus vaccine in BALB/c mice. Vaccine 32, 5975-5982 (2014).

12. Wang, C. et al. Novel chimeric virus-like particles vaccine displaying MERS-CoV receptor-binding domain induce specific humoral and cellular immune response in mice. Antivir. Res. 140, 55-61 (2017).

13. Lan, J. et al. Tailoring subunit vaccine immunity with adjuvant combinations and delivery routes using the Middle East respiratory coronavirus (MERS-CoV) receptor-binding domain as an antigen. PLOS ONE 9, e112602 (2014).

14. Alharbi, N. K. et al. ChAdOx1 and MVA based vaccine candidates against MERS$\mathrm{CoV}$ elicit neutralising antibodies and cellular immune responses in mice. Vaccine 35, 3780-3788 (2017)

15. Rodriguez-Limas, W. A., Sekar, K. \& Tyo, K. E. J. Virus-like particles: the future of microbial factories and cell-free systems as platforms for vaccine development. Curr. Opin. Biotech. 24, 1089-1093 (2013).

16. Reddy, S. T. et al. Exploiting lymphatic transport and complement activation in nanoparticle vaccines. Nat. Biotechnol. 25, 1159-1164 (2007).

17. Mohsen, M. O., Gomes, A. C., Vogel, M. \& Bachmann, M. F. Interaction of Viral Capsid-Derived Virus-Like Particles (VLPs) with the Innate Immune System. Vaccines (Basel). 6, 37 (2018).

18. Bachmann, M. F. \& Jennings, G. T. Vaccine delivery: a matter of size, geometry, kinetics and molecular patterns. Nat. Rev. Immunol. 10, 787-796 (2010).

19. Mohsen, M. O., Zha, L., Cabral-Miranda, G. \& Bachmann, M. F. Major findings and recent advances in virus-like particle (VLP)-based vaccines. Semin Immunol. 34 123-132 (2017)

20. Mohsen, M. O., Augusto, G. \& Bachmann, M. F. The 3Ds in virus-like particle basedvaccines: "Design, Delivery and Dynamics". Immunol. Rev. 296, 155-168 (2020).

21. Balke, I. \& Zeltins, A. Recent advances in the use of plant virus-like particles as vaccines. Viruses-Basel. 12, 270 (2020).

22. Bessa, J., Kopf, M. \& Bachmann, M. F. Cutting edge: IL-21 and TLR signaling regulate germinal center responses in a B cell-intrinsic manner. J. Immunol. 184, 4615-4619 (2010).

23. Bessa, J. et al. Efficient induction of mucosal and systemic immune responses by virus-like particles administered intranasally: implications for vaccine design. Eur. J. Immunol. 38, 114-126 (2008).

24. Bessa, J. et al. Low-affinity B cells transport viral particles from the lung to the spleen to initiate antibody responses. Proc. Natl Acad. Sci. USA. 109, 20566-20571 (2012).

25. Zinkhan, S. et al. The impact of size on particle drainage dynamics and antibody response. J. Control Release 331, 296-308 (2021).

26. Mohsen, M. O. et al. Delivering adjuvants and antigens in separate nanoparticles eliminates the need of physical linkage for effective vaccination. J. Control Release 251, 92-100 (2017)

27. Mohsen, M. O. et al. Targeting mutated plus germline epitopes confers preclinical efficacy of an instantly formulated cancer nano-vaccine. Front Immunol. 10, 1015 (2019).

28. Mohsen, M. O. et al. Correction to: vaccination with nanoparticles combined with micro-adjuvants protects against cancer. J. Immunother. Cancer 7, 137 (2019).

29. Zeltins, A. et al. Incorporation of tetanus-epitope into virus-like particles achieves vaccine responses even in older recipients in models of psoriasis, Alzheimer's and cat allergy. Npj Vaccines. 2, 30 (2017).

30. Walls, A. C. et al. Unexpected receptor functional mimicry elucidates activation of coronavirus fusion. Cell 183, 1732 (2020).

31. Liu, X. et al. AP205 VLPs based on dimerized capsid proteins accommodate RBM domain of SARS-CoV-2 and serve as an attractive vaccine candidate. Vaccines (Basel). 9, 403 (2021).
32. Wang, C. et al. MERS-CoV virus-like particles produced in insect cells induce specific humoural and cellular imminity in rhesus macaques. Oncotarget $\mathbf{8}$ 12686-12694 (2017).

33. Krueger, C. C. et al. RNA and toll-like receptor 7 license the generation of superior secondary plasma cells at multiple levels in a B cell intrinsic fashion. Front Immunol. 10, 736 (2019).

34. Sun, Z. et al. Mass spectrometry analysis of newly emerging coronavirus HCoV-19 spike protein and human ACE2 reveals camouflaging glycans and unique posttranslational modifications. Engineering (Beijing). 2020.

35. Grant, O. C., Montgomery, D., Ito, K. \& Woods, R. J. Analysis of the SARS-CoV-2 spike protein glycan shield reveals implications for immune recognition. Sci. Rep. 10, 14991 (2020).

36. Gomes, A. C., Roesti, E. S., El-Turabi, A. \& Bachmann, M. F. Type of RNA Packed in VLPs Impacts IgG Class Switching-Implications for an Influenza Vaccine Design. Vaccines (Basel). 7, 47 (2019).

37. Rodriguez, A. et al. Role of $\lg A$ in the defense against respiratory infections $\lg A$ deficient mice exhibited increased susceptibility to intranasal infection with Mycobacterium bovis BCG. Vaccine 23, 2565-2572 (2005).

38. VanBlargan, L. A., Goo, L. \& Pierson, T. C. Deconstructing the antiviral neutralizing antibody response: implications for vaccine development and immunity. Microbiol Mol. Biol. Rev. 80, 989-1010 (2016).

\section{ACKNOWLEDGEMENTS}

This work was supported by MRC-HMC (grant 29032016), Qatar National Research Fund (PDRA grant PDRA4-0118-18002) and by the Swiss National Science Foundation (SNF 310030_185114 and SNF 310030_179165). We would like to thank Prof. Daniel Speiser for his thorough editing of the paper.

\section{AUTHOR CONTRIBUTIONS}

Design of experiments, acquisition of data, interpretation and analysis of data: M.O. M., D.R., I.B., B.M., Z.G., K.T., M.V., A.Z. and M.F.B. Writing, revision and editing of paper: M.O.M., D.R., A.Z. and M.F.B. Technical, material and tool support: V.I., G.N. and S.D. Study supervision: M.O.M. and M.F.B. All authors read and approved the final paper.

\section{COMPETING INTERESTS}

M. F. Bachmann is a board member of Saiba $A G$, holds the patent of $\mathrm{CUMV}_{\Pi \pi}-\mathrm{VLPs}$.

\section{ADDITIONAL INFORMATION}

Supplementary information The online version contains supplementary material available at https://doi.org/10.1038/s41541-021-00365-w.

Correspondence and requests for materials should be addressed to M.O.M.

Reprints and permission information is available at http://www.nature.com/ reprints

Publisher's note Springer Nature remains neutral with regard to jurisdictional claims in published maps and institutional affiliations.

\footnotetext{
Open Access This article is licensed under a Creative Commons Attribution 4.0 International License, which permits use, sharing, adaptation, distribution and reproduction in any medium or format, as long as you give appropriate credit to the original author(s) and the source, provide a link to the Creative Commons license, and indicate if changes were made. The images or other third party material in this article are included in the article's Creative Commons license, unless indicated otherwise in a credit line to the material. If material is not included in the article's Creative Commons license and your intended use is not permitted by statutory regulation or exceeds the permitted use, you will need to obtain permission directly from the copyright holder. To view a copy of this license, visit http://creativecommons. org/licenses/by/4.0/.
}

(c) The Author(s) 2021 